\title{
Population-based surveillance of asthma among workers in British Columbia, Canada
}

\author{
M. Koehoorn, PhD (1); L. Tamburic, BSc (2); C. B. McLeod, PhD (2); P. A. Demers, PhD (3); L. Lynd, PhD (4); \\ S. M. Kennedy, PhD (1)
}

This article has been peer reviewed.

\begin{abstract}
Introduction: Population-based health databases were used for the surveillance of asthma among workers in British Columbia for the period 1999 to 2003. The purpose was to identify high-risk groups of workers with asthma for further investigation, education and prevention.
\end{abstract}

Methods: Workers were identified using an employer-paid health premium field in the provincial health registry, and were linked to their physician visit, hospitalization, workers' compensation and pharmaceutical records; asthma cases were defined by the presence of an asthma diagnosis (International Classification of Diseases [ICD]-9-493) in these health records. Workers were assigned to an "at-risk" exposure group based on their industry of employment.

Results: For males, significantly higher asthma rates were observed for workers in the Utilities, Transport/Warehousing, Wood and Paper Manufacturing (Sawmills), Health Care/Social Assistance and Education industries. For females, significantly higher rates were found for those working in the Waste Management/Remediation and Health Care/ Social Assistance industries.

Conclusion: The data confirm a high prevalence of active asthma in the working population of British Columbia, and in particular, higher rates among females compared to males and in industries with known respiratory sensitizers such as dust and chemical exposures.

Keywords: population surveillance, occupational diseases, asthma, British Columbia

\section{Introduction}

Exposure to occupational hazards accounts for a significant proportion of the national and global burden of disease, which could be substantially reduced through recognition, measurement and controls. Workrelated asthma is considered to be the most common work-related respiratory disease in industrialized countries. ${ }^{1}$ Occupational exposures, including organic and inorganic dusts, and biological agents, such as flour/grains, plants, fur, feathers, fungi and various types of woods, are important risk factors for both the initiation and aggravation of adult asthma. ${ }^{2,3}$ The American Thoracic Society, ${ }^{4}$ in their review of the literature based largely on studies in industrialized countries, estimated that approximately $15 \%$ of asthma was due to occupational exposures, although other estimates of the attributable risk proportions are as high as $29 \%$ and $36.5 \%$. 5,6 Workers' compensation statistics often do not reflect this level of risk in the population. ${ }^{7}$ There are limitations in the use of accepted workers' compensation claim data for surveillance, in particular the ability of the data systems to ascertain cases of disease due to underreporting, ${ }^{8}$ a lack of recognition of the relationship between some exposures and health outcomes, or emerging relationships that are not yet recognized without systematic data collection.

The National Institute for Occupational Safety and Health (NIOSH) in the United States highlighted the need for improved surveillance research methods. ${ }^{9-11} \mathrm{NIOSH}$ specifically mentions the use of linked data sources, such as administrative and health care data, to identify populations that may not be well captured in existing surveillance systems. We investigated multiple administrative health databases for population-based surveillance of asthma rates by industry of employment among workers in the Canadian province of British Columbia. We also investigated the face validity of this surveillance approach by investigating asthma rates among high-risk groups using an exposure matrix. ${ }^{2}$ We hypothesized that the rate would be higher among workers in industries with suspected or known allergens such as wood dust (i.e. wood and paper manufacturing), moulds or endotoxins (e.g. schools) and latex/glutaraldehyde or industrial cleaning agents (e.g. health care services)..$^{2,12,13}$

We had access to health databases for population health and health services

Author references:

1. School of Population and Public Health, University of British Columbia, Vancouver, British Columbia, Canada

2. Centre for Health Services and Policy Research, University of British Columbia, Vancouver, British Columbia, Canada

3. Occupational Cancer Research Centre, Cancer Care Ontario, Toronto, Ontario, Canada

4. Pharmaceutical Sciences, University of British Columbia, Vancouver, British Columbia, Canada

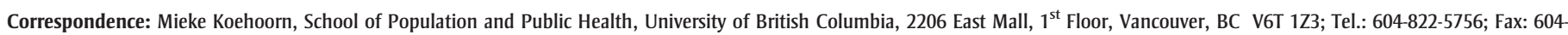
822-4994; Email: mieke.koehoorn@ubc.ca 
research via Population Data BC. ${ }^{14}$ The data included longitudinal, personspecific, de-identified health data on British Columbia's 4.5 million residents across multiple data sources. The use of these linked administrative health databases provided a novel approach to work-related health surveillance, beyond workers' compensation statistics. As surveillance tools, the databases can provide evidence of the relationship between exposures and disease outcomes for further investigation of high-risk groups and recognition of work-related illness, as well as education and prevention efforts.

\section{Methods}

\section{Study population}

Using the provincial health registry, we identified individuals aged 15 to 64 years who had been continuously registered (i.e. living in the province) for a minimum of 3 years at entry into the study. The study population excluded individuals with missing data on sex or with a diagnosis of chronic obstructive pulmonary disease (International Classification of Disease, version 9 [ICD-9] codes 491, 492, 496) given the potential overlap between asthma and chronic obstructive lung disease diagnoses in older adults. Among continuously registered residents, we identified workers using an employer-paid health premium code in the health registry. As a dynamic study population, individuals could enter the study at any time from 1999 to 2003 providing they met the inclusion criteria.

\section{Exposure groups}

The employer-paid health premium codes were used to assign a standardized industry of employment (North American Industry Classification System or NAICS code ${ }^{15}$ ). To identify industries with known or suspected allergen exposures, defined here as at-risk or high-risk industries, we used an asthma-specific job exposure matrix ${ }^{2}$ previously developed for population-based studies. All matches between the matrix and our study sample were reviewed by investigators (MK, PD) with expertise in occupational asthma and occupational hygiene as well as knowledge of British Columbia industries and their exposures.

\section{Health data sources}

Health data on physician visits and hospitalizations, workers' compensation claims and filled prescriptions for the population of British Columbia were available to researchers for approved projects from the Ministry of Health, WorkSafeBC and PharmaNet, respectively, via Population Data BC. Data are linkable at the individual level but were provided to researchers with personal identifiers removed from the records. Use of the data for this project was governed by data access and confidentiality agreements between the data stewards and the researchers, as well as by the Behavioural Ethics Research Board of the University of British Columbia (Certificate \#B05-0664). Given a universal health care system for physician visits and hospitalizations, over $93 \%$ workforce coverage by the workers' compensation system and a provincial prescription database (all prescriptions filed in pharmacies in British Columbia), the health data are considered comprehensive for provincial residents. Follow-up of asthma outcomes was limited to the study years given the availability of health records across all data sources and the availability of industry of employment codes in the provincial health registry.

\section{Case definition}

Physician-diagnosed asthma was identified using the ICD-9 code 493. The case definition was met if a worker had one diagnosed hospitalization, two diagnosed physician visits in a 12-month period, one diagnosed workers' compensation claim, or two prescriptions for any asthmarelated drugs confirmed by at least one diagnosed physician visit within a 12 -month period. $^{7}$ In the event of two physician visits or two prescriptions within 12 months but spanning calendar years, the year of the first visit or prescription was attributed to the asthma case. Asthma-related drugs were defined by the pharmacist on the research team (LL) and extracted based on the Drug Identification Number (list available upon request).
For the purposes of surveillance, we were interested in "active" asthma among the working study population during each year of follow-up. Focusing on active asthma is important as both asthma onset (incident cases during follow-up) and aggravation of existing asthma (prevalent cases requiring health care during followup) are compensable conditions associated with workplace exposures in British Columbia. Individuals who met the case definition before entry into the study were prevalent cases. Individuals who met the case definition during the study follow-up period (i.e. were asthmafree for a minimum of three years before entry into the study) were incident cases. Incident cases were considered active asthma in the year they became an incident case and each subsequent year that they had a health care contact for asthma. Prevalent cases were considered active asthma in each year that they had a health care contact for asthma. Active asthma was defined as contact with the health care system (physician visit, hospitalization, prescription or compensation claim) during the year.

\section{Analysis}

Rates of active asthma were calculated per year of follow-up using Stata version 10.1 (StataCorp, College Station, TX, US). Ageand sex-adjusted rates with $95 \%$ confidence intervals (CIs) were compared by industry of employment groups and for high-risk versus low-risk industries.

\section{Results}

\section{Study population}

A total of 2.7 million residents of working age were continuously registered for health services during the study period, 1999 to 2003 . Less than $0.3 \%$ of individuals were excluded for missing data on sex $(n=4001)$ and for a diagnosis of chronic obstructive pulmonary disease $(n=3456)$. Altogether, 908896 workers were identified by industry of employment using the employer-paid health premium codes. They represented $33 \%$ of the registered population but $60 \%$ of the working population in British Columbia. ${ }^{16}$ This method of identifying a population-based 
working cohort using the employer-paid health premium codes underrepresents the self-employed, small worksites (i.e. $<5$ employees) and females as these groups have lower rates of employer-paid health premiums.

In 2003, females made up $42.8 \%$ of the included working study population, compared to $47.2 \%$ of the overall British Columbia workforce ${ }^{17}$ and to $50.6 \%$ in the continuously registered population from which the working population was drawn. The mean age of the working study population was 42.1 years; this compares to an average age of 40.7 years among workers in the province ${ }^{18}$ and to 39.4 years among the registered population.

The included working study population was distributed over 843 distinct industrial sectors. Males were concentrated in Wood and Paper Manufacturing (14.8\% in 1999 and $13.4 \%$ in 2003), Public Administration (11.7\% and $11.0 \%)$ and Transport and Warehousing $(8.2 \%$ and $7.7 \%)$. Females were concentrated in Health Care and Social Assistance (22.8\% and 23.3\%) and Education (14.9\% and $14.8 \%)$. This is comparable to the top industries of employment by gender in the overall provincial workforce, with the exception of Trades for both genders, Construction among males and Accommodation and Food Services among females. ${ }^{19}$

\section{Active asthma rates}

Overall, we identified a total of 41966 cases of asthma, of which 30080 were prevalent at the time of entry into the study (for a prevalence rate of 33.1 cases per 1000 workers) and 11886 were new cases identified during the study follow-up period (for a cumulative incidence rate of 13.1 cases per 1000 workers). The majority of asthma cases were identified through physician visits $(20.8 \%)$ or a combination of prescriptions with a physician visit (55.2\%). Only 302 cases $(0.7 \%)$ were captured by a workers' compensation claim.

Rates of active asthma for the years 1999 to 2003 (Table 1) ranged from 22.3 to 26.2 cases per 1000 male workers, and from 33.7 to 40.6 cases per 1000 female workers. A small annual increase was observed from 1999 through to 2003. Ageadjusted active asthma rates by industry are shown for the year 2003 only, as results for 1999 to 2002 were similar (Table 2). For males, the active asthma rate was significantly higher than the overall rate in the working population for workers employed in Wood and Paper Manufacturing (including Sawmills), Health Care and Social Assistance, and Schools industries. Higher rates (although $95 \%$ confidence interval $[\mathrm{CI}]$ included the rate for the working population) were also observed for male workers in the Utilities; Transport and Warehousing; Educational Services; Mining, Oil and Gas; Finance and Insurance; and Public Administration industries. For females, the active asthma rate was significantly higher in the Waste Management and Remediation and Health Care and Social Assistance (including general hospitals and nursing care facilities) industries. Higher rates (95\% CI overlapped with the overall rate in the working population) were also observed for the female workers in the Public Administration, Information and Cultural, and Educational Services industries.

During follow-up, rates of active asthma for "at-risk" industries among males ranged from 25.2 to 28.6 cases per 1000 workers and were higher than those observed for "low-risk" industries. Rates for "at-risk" industries among females ranged from 35.2 to 41.6 cases per 1000 workers. While rates tended to be slightly higher for at-risk industries compared to low-risk industries for females, the differences were not as consistent or as high as that observed for males.

\section{Discussion}

The purpose of this study was to investigate the feasibility of using linked health data for population-based surveillance of asthma among workers and to investigate at-risk industry groups for on-going monitoring and future prevention efforts. To do this we estimated the active asthma rate among a population-based workforce sample by industry of employment and among at-risk industry groups with known or suspected allergen exposures.

The use of an active asthma measure for the surveillance of work-related disease does not enable comparisons with many other studies using more traditional measures of asthma incidence and prevalence for population-based estimates. Nevertheless, our overall annual rate of active asthma of approximately 30 cases per 1000 workers is consistent with an

TABLE 1

Active asthma ${ }^{a}$ rates per 1000 workers, British Columbia, Canada, 1999-2003

\begin{tabular}{|c|c|c|c|c|c|}
\hline & $\begin{array}{c}1999 \\
\text { Rate }(95 \% \mathrm{Cl})\end{array}$ & $\begin{array}{c}2000 \\
\text { Rate }(95 \% \mathrm{CI})\end{array}$ & $\begin{array}{c}2001 \\
\text { Rate }(95 \% \mathrm{Cl})\end{array}$ & $\begin{array}{c}2002 \\
\text { Rate }(95 \% \mathrm{Cl})\end{array}$ & $\begin{array}{c}2003 \\
\text { Rate }(95 \% \mathrm{Cl})\end{array}$ \\
\hline Males & $22.3(21.8-22.7)$ & $23.7(23.2-24.1)$ & $25.0(24.5-25.5)$ & $25.5(25.0-25.9)$ & $26.2(25.7-26.7)$ \\
\hline Low risk industries & $21.5(20.9-22.0)$ & $22.8(22.3-23.3)$ & $24.3(23.8-24.9)$ & $24.8(24.2-25.3)$ & $25.6(25.0-26.2)$ \\
\hline Females & $33.7(33.0-34.4)$ & $36.1(35.4-36.8)$ & $37.4(36.7-38.1)$ & $38.2(37.5-38.9)$ & $40.6(39.9-41.3)$ \\
\hline High risk industries & $35.2(33.7-36.6)$ & $36.0(34.5-37.5)$ & $38.0(36.5-39.4)$ & $38.2(36.8-39.7)$ & $41.6(40.1-43.0)$ \\
\hline
\end{tabular}

Abbreviations: $\mathrm{Cl}$, confidence interval.

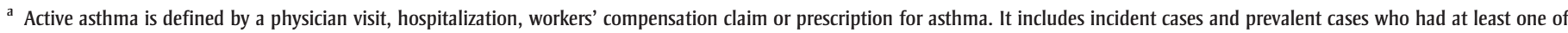
these health care contacts in the year of follow-up. 
TABLE 2

Age-adjusted active $^{\mathrm{a}}$ asthma rates per 1000 workers, British Columbia, Canada, 2003

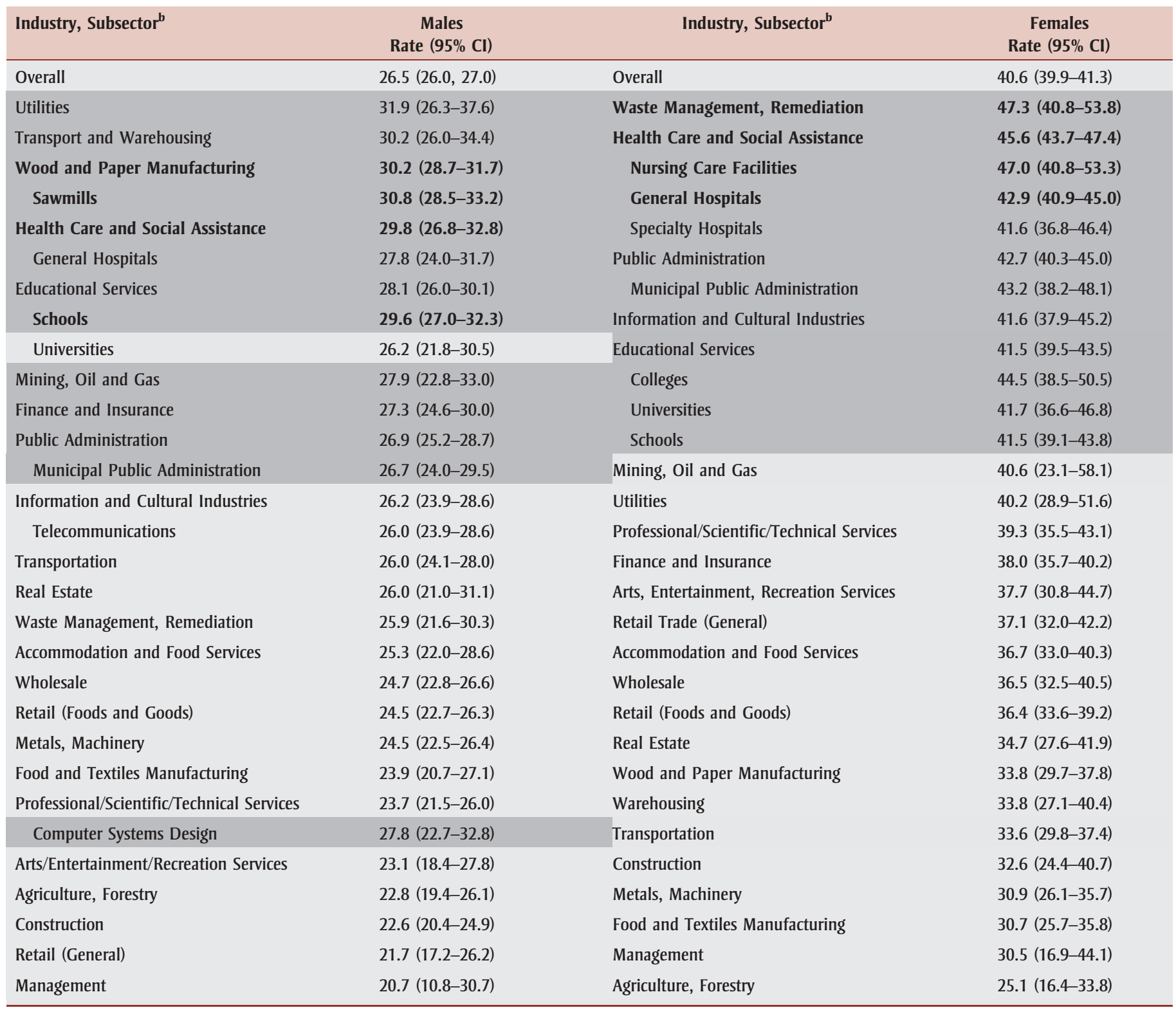

Abbreviation: $\mathrm{Cl}$, confidence interval.

Note: grey shading, rate is higher than overall rate in working population; bold, $95 \% \mathrm{Cl}$ does not include the overall rate.

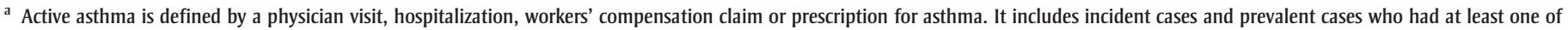
these health care contacts for asthma in 2003.

${ }^{\mathrm{b}}$ North American Industry Classification System (NAICS) Coding ${ }^{15}$ with subsectors where sample size allows.

overall rate of $3 \%$ (or 30 cases per 1000) for active asthma (as defined by an asthma attack in the past year) observed in the European Community Respiratory Health Survey (ECRHS). ${ }^{20}$ Our study definition of active asthma includes incident as well as prevalent cases requiring health care, and we expected our estimates to fall within the range of previous incidence and prevalence studies. An asthma incidence rate of $3 \%$ (or 30 cases per 1000 workers) among high-risk or exposed occupations in the ECRHS II study ${ }^{21}$ falls within the range we observed in our study among high-risk groups of male and female workers. Estimates of the prevalence of work-related asthma using administrative data from a sample of the labour force in the Canadian province of Manitoba found rates as high as 48 cases per 1000 workers among some occupational groups, ${ }^{12}$ close to our highest estimate observed among women in high-risk groups. Observed differences with previous studies may be attributed to different case ascertainment definitions, trying to compare with an annual active asthma rate, and the use of industry versus occupation to assign exposure risk. Finally, a study of new-onset adult asthma among a working sample in the province of Alberta found an incidence rate of $1.6 \%$ (or 16 cases per 1000$)^{13}$ over a 10 -year 
follow-up period. Although higher than our estimate of cumulative incidence at 13 cases per 1000 workers, this may be explained by differences in the definition for case ascertainment (one physician visit for asthma in the Alberta study). Collectively, our surveillance system produced estimates that were within the range of other studies despite differences in methods, case definitions and workforce characteristics.

The higher rate of asthma among female workers compared to male workers is consistent with surveillance results from the neighbouring province of Alberta, ${ }^{13}$ as well as self-reported estimates from national health surveys ${ }^{22}$ and those from other jurisdictions. ${ }^{5}$ The Alberta study relied on health records similar to our methodology for case ascertainment among a worker population and found twice the incidence rate of adult asthma among females compared to males, ${ }^{13}$ consistent with our findings. Again, higher rates in the current study may be due to our case definition of active asthma in the follow-up year, but females having almost twice the rate of males overall was consistent with our findings. Possible occupational explanations for the gender difference in a working population include more females working in high-risk jobs (i.e. teaching or health care) ${ }^{17}$ or in highrisk jobs with exposures that are not as obvious or amenable to personal protective equipment, leading to more active asthma symptoms and medical attention (i.e. food services versus wood and paper products $^{23}$ ). It may also reflect a gender difference associated with the "healthy worker effect" whereby males have a "stronger healthy worker hire effect" while females have a "stronger healthy worker survivor effect.,"24,25 With a strong healthy worker hire effect, males with childhood-onset asthma or existing adultonset asthma would be less likely to be hired into high-risk jobs. With a stronger healthy worker survivor effect, females would be more likely to be in the workforce with asthma (although less likely to remain at work over the longer term). It may also be plausible that women are more likely to work with asthma symptoms. Evidence suggests that socioeconomic factors may differentially impact vulnerable groups such as females with less job mobility, placing them at increased risk for adverse effects of workplace exposures. ${ }^{24,26}$

Our study identified industries with higher than average rates of active asthma. Industries dealing with wood/wood dust as well as individuals working in schools and health services were at an increased risk of asthma compared with those working in other industries. This is in keeping with known or suspected exposures related to dusts, moulds/endotoxins, and latex/glutaraldehyde or industrial cleaning agents. $^{2}$ It is also consistent with surveillance studies investigating high-risk groups by occupation, including the Manitoba and Alberta studies that identified a higher risk among workers in teaching and related occupations. ${ }^{12,13}$ The previous studies were able to identify other high-risk groups likely due to differences in type of employment by province (i.e. forestry is a major industry in British Columbia) but also due to a finer level of detail for exposures by occupation. For example, the Alberta study was able to identify a higher risk among workers in industries dealing with flour/ food, fibreglass and vehicles. Similarly, the Manitoba study identified higher risks among fabricating, installing and repairing occupations of electrical, electronic and related equipment.

Conversely, some industrial groups such as Metals/Machinery or Manufacturing (Food and Textiles) did not appear at an increased risk relative to other industries. The reliance on industry of employment as a surrogate measure of exposure for at-risk jobs in this surveillance project may be subject to more misclassification for these types of industries. Industrial groups such as Manufacturing may be made up of multiple and diverse occupational groups. Some have known or suspected exposures such as textiles, wood dust or metal working fluids, but others do not (i.e. beverage manufacturing), resulting in a conservative bias on the estimates. Industries such as Educational Services or Health Services, on the other hand, may be dominated by several large occupational groups such as teachers or nurses/cleaners all with known or suspected allergens (e.g. mould or chemical irritants), resulting in better estimates of exposure using this method of at-risk industries of employment. Overall, the misclassification of exposure using industry of employment exerts a conservative bias attenuating the risk estimates. Ultimately, it would be ideal to improve this surveillance method with more detailed occupation information at the population level. This is currently not captured by any of the administrative datasets with the exception of the workers' compensation claim records. Including occupation of employment in medical registries or health records/databases would be an invaluable source of data for surveillance studies, as concluded by others involved in similar work. ${ }^{27}$ Novel approaches to obtaining occupation and industry of employment data from administrative databases for populationbased health surveillance are also warranted, as was done by Cherry et al. in Alberta. ${ }^{13}$

While Ministry of Health employer coding is assumed to be valid for billing purposes, there may still be limitations in terms of assigning exposure based on the industry of employment codes. Not all individuals within an industry are working in an occupation with exposures, and we were not able to investigate high-risk occupational groups. We relied on an exposure matrix to investigate at-risk industrial groups; some misclassification with bias towards the null is unavoidable using this approach and may explain why we did not observe greater differences between the high- and low-risk groups. It is also possible that the misclassification is greater for women than men using industry coding for exposure as women may work in more diverse occupations in highrisk industries such as construction. ${ }^{28}$ This would explain the smaller observed differences in asthma rates between high- and low-exposed industrial groups for women.

There is also some uncertainty about whether the industry of employment at the time of case ascertainment is the industry of exposure. Current symptoms may be as a result of past exposures (i.e. employment in an industry other than the current one). Our population-based 
surveillance approach overcomes some of the biases associated with the healthy worker effect in previous occupational cohort studies and provides information about asthma in the working population by following workers forward even after they leave the workforce (or if they change industries). Further, as we have emphasized, women as well as self-employed workers or those who work for small employers are underrepresented using the employer-paid health premium codes in the provincial medical registry.

The years of follow-up were limited based on the availability of the industry coding. Workplace processes (and exposures) have not changed so dramatically over the past decade as to render these findings irrelevant for workers in the same industries today (i.e. forestry workers are still exposed to wood dust, teachers to moulds or endotoxins, cleaners to industrial cleaning agents, and metal workers to metal working fluids), and the job exposure matrix used in this study is based on known risk factors for asthma still present in industries. The retrospective data available for this study represent the only known source of employment codes for a large proportion of the working population, linked to multiple health databases. An advantage of using population-based administrative data is that the larger number of individuals involved allows for robust analysis of age, sex and other demographic trends, compared to data limited by sample size. Another advantage is that the ability to link multiple health databases improves case ascertainment for occupational outcomes. ${ }^{29}$

We are not suggesting that all of the cases of asthma among workers in our study are work-related, but it appears that workers' compensation claims data underestimate asthma in the population, necessitating the use of additional data sources to capture asthma among workers and identify work groups with higher rates. Less than $1 \%$ of our cases were captured by the workers' compensation system as an accepted claim ${ }^{7}$ despite a recognized population-attributable risk estimate of asthma associated with occupational exposures of $15 \%,{ }^{4}$ including Canadian estimates. $^{30,31}$ Given the face validity associated with higher rates among industries with known allergens, the current study offers a surveillance tool for ongoing monitoring among at-risk groups, as well as evidence of the need for additional education on the association between workplace exposures and asthma morbidity. The study also offers a tool for identifying new or emerging at-risk groups for further investigation, such as the workers in the waste management industry and the public sector, as we observed.

\section{Acknowledgments}

This research was supported in part by operating funds provided by AllerGen NCE Inc (The Allergy, Genes and Environment Network, Networks of Centres of Excellence of Canada) and WorkSafeBC (the Workers Compensation Board of British Columbia). M. Koehoorn was supported in part by a Michael Smith Foundation for Health Research Senior Scholar Award. The authors wish to thank Population Data BC as a resource for access to linked, administrative health data for research purposes. The British Columbia Ministry of Health, WorkSafeBC and PharmaNet approved access to and use of the data facilitated by Population Data BC for this study.

\section{References}

1. Kogevinas M, Anto JM, Sunyer J, Tobias A, Kromhout H, Burney P. Occupational asthma in Europe and other industrialised areas: a population-based study. European Community Respiratory Health Survey Study Group. Lancet. 1999 May 22; 353(9166):1750-4.

2. Kennedy SM, Le Moual N, Choudat D, Kauffmann F. Development of an asthma specific job exposure matrix and its application in the epidemiological study of genetics and environment in asthma (EGEA). Occup Environ Med. 2000;57:635-41.

3. Le Moual N, Kennedy SM, Kauffmann F. Occupational exposures and asthma in 14,000 adults from the general population. Am J Epidemiol. 2004;160(11):1108-16.
4. Balmes J, Becklake $\mathrm{M}$, Blanc $\mathrm{P}$, Henneberger P, Kreiss K, Mapp C, et al. American Thoracic Society statement on occupational contribution to the burden of airway disease. Am J Respir Crit Care Med. 2003;167(5):787-97.

5. Karjalainen A, Kurppa K, Martikainen R, Klaukka T, Karjalainen J. Work is related to a substantial portion of adult-onset asthma incidence in the Finnish population. Am J Respir Crit Care Med. 2001;164(4):565-8.

6. Arif AA, Whitehead LW, Delclos GL, Tortolero SR, Lee ES. Prevalence and risk factors of work related asthma by industry among United States workers: data from the third national health and nutrition examination survey (1988-94). Occ Env Med. 2002;59(8):505-11.

7. McLeod CB, Bogyo T, Demers P, Edeer D, Hertzman C, Kennedy S, et al. Asthma in British Columbia [Internet]. Vancouver (BC): Centre for Health Services and Policy Research, University of British Columbia; 2007 Jan [cited 2011 Jul 19]. Available from: http://pwhr.sites.olt.ubc.ca/files/2012/03

/Asthma-Report-2007.pdf

8. Kraut A. Estimates of the extent of morbidity and mortality due to occupational diseases in Canada. Am $\mathrm{J}$ Ind Med. 1994;25(2):267-78.

9. National Institute for Occupational Health and Safety (NIOSH). Tracking occupational injuries, illnesses, and hazards: the NIOSH surveillance strategic plan. Cincinnati (OH): National Institute for Occupational Health and Safety; 2001. Report No.: DHHS (NIOSH) Publication Number 2001-118.

10. Souza K, Steege AL, Baron SL. Surveillance of occupational health disparities: challenges and opportunities. Am J Ind Med. 2010;53:84-94.

11. National Occupational Research Agenda (NORA). Traumatic occupational injury research needs and priorities: a report by the NORA traumatic injury team. Cincinnati (OH): National Institute for Occupational Health and Safety; 1998. Report No.: DHHS (NIOSH) Publication Number 98-134 
12. Kraut A, Walld R, Mustard C. Prevalence of physician-diagnosed asthma by occupational groupings in Manitoba, Canada. Am J Ind Med. 1997;32(3):275-87.

13. Cherry N, Beach J, Burstyn I, Fan X, Guo N, Kapur N. Data linkage to estimate the extent and distribution of occupational disease: new onset adult asthma in Alberta, Canada. Am J Ind Med. 2009; 52(11):831-40.

14. Population Data BC. Research data access framework [Internet]. Vancouver (BC): Population Data BC, University of British Columbia. [cited 2011 Jul 20]. Available from: http://www.popdata.bc.ca/dataaccess/rdaf

15. Statistics Canada. North American Industry Classification System (NAICS) 2002. Ottawa (ON): Government of Canada, Ministry of Industry; 2003.

16. Tamburic L, McLeod C, Xu F, Demers P, Kennedy S, Lynd L, et al. Asthma in BC workers: surveillance using new occupational research capacity in the BC Linked Health Database. Canadian Association for Research on Work and Health (CARWH) conference (poster presentation); June 15-17 2008; Montreal (QC). [cited 2011 Jul 20]. Available from: http://pwhr.sites.olt.ubc.ca /files/2012/03/Asthma-poster-from-CARWH -2008.pdf

17. BCStats. Employment by class of worker, industry, and gender, BC - annual averages (thousands of persons) [Internet]. Ottawa (ON): Statistics Canada - Labour Force Survey - CANSIM Table 282-0012; [cited 2012 May 14]. Available from: http: //www.bcstats.gov.bc.ca/Files/16005079 -7667-4c0a-ac45-bd3316341a4c/Employment byClassofWorker.pdf

18. BCStats. BC's Ageing Workforce. Victoria (BC): Infoline [Internet]. 2010 Aug 13 [cited 2011 Jul 20];10(32):3-5. Available from: http://www.bcstats.gov.bc.ca/Files /796b76ad-c446-46b7-b6b4-362f68b51f8d /InfolineBCsAgeingWorkforce.pdf

19. BCStats. British Columbia employment by detailed industry, annual averages [Internet]. Victoria (BC): Government of British Columbia; 2011 Feb 8 [cited 2011 Jul 20]. Available from: https://www.bcstats .gov.bc.ca/Files/2bd86b08-a46b-4ed3-88e6 -b14e27bda5b3/EmploymentbyIndustry.pdf
20. European Community Respiratory Health Survey. Variations in the prevalence of respiratory symptoms, self-reported asthma attacks, and use of asthma medication in the European Community Respiratory Health Survey (ECRHS). Eur Respir J. 1996 Apr;9(4):687-95.

21. Kogevinas M, Zock JP, Jarvis D, Kromhout $\mathrm{H}$, Lillienberg L, Plana E, et al. Exposure to substances in the workplace and newonset asthma: an international prospective population-based study (ECRHS-II). Lancet. 2007;370(9584):336-41.

22. Garzia NA. Surveillance of asthma in relation to work among Canada's adult population [dissertation]. Vancouver (BC): University of British Columbia; 2008 [cited 2011 Jul 20]. Available from: https://circle.ubc.ca/handle/2429/2471

23. BCStats. Earnings \& Employment Trends, June 2010: Woman enough to do the job: women's integration into traditionally male-dominated occupations. Victoria (BC): Government of British Columbia; 2010 Jun [cited 2012 May 14]. Available from: http://www.bcstats.gov.bc.ca/Files /669c1e5b-5a2d-44f1-996d-77e30c10df9c /WomanEnoughtoDotheJobWomens IntegrationintoTraditionallyMale-

DominatedOccupations.pdf

24. Le Moual N, Kauffmann F, Eisen EA, Kennedy SM. The healthy worker effect in asthma: work may cause asthma, but asthma may also influence work. Am J Resp Crit Care. 2008;177(1):4-10.

25. Lea CS, Hertz-Picciotto I, Andersen A, ChangClaude J, Olsen JH, Pesatori AC, et al. Gender differences in the healthy worker effect among synthetic vitreous fiber workers. Am J Epidemiol. 1999;150(10):1099-106.

26. Marabini A, Dimich-Ward H, Kwan SY, Kennedy SM, Waxler-Morrison N, ChanYeung M. Clinical and socioeconomic features of subjects with red cedar asthma. A follow-up study. Chest. 1993;104(3):821-4.

27. Suarthana E, McFadden JD, Laney AS, Kreiss K, Anderson HA, Hunt DC, et al. Occupational distribution of persons with confirmed 2009 H1N1 influenza. J Occup Environ Med. 2010;52(12):1212-6.
28. Statistics Canada. Public use microdata file (PUMF): Labour Force Survey - Data File (LFS). Ottawa (ON): Statistics Canada; [cited 2011 Mar 15]. Available from: http: //www.statcan.gc.ca/cgi-bin/imdb/p2SV.pl? Function $=$ getDatafileData\&Item_Id $=55456$ \&lang $=e n \& d b=i m d b \& a d m=8 \& d i s=2$

29. Smith GS, Veazie MA, Benjamin KL. The use of sentinel injury deaths to evaluate the quality of multiple sources of reporting of occupational injuries. Ann Epidemiol. 2005;15(3):219-27.

30. Tarlo SM, Leung K, Broder I, Silverman F, Holness DL. Asthmatic subjects symptomatically worse at work: prevalence and characterization among a general asthma clinic population. Chest. 2000;118(5):1309-14.

31. Johnson AR, Dimich-Ward HD, Manfreda J, Becklake MR, Ernst P, Sears MR, et al. Occupational asthma in adults in six Canadian communities. Am J Respir Crit Care Med. 2000;162(2):2058-62. 